\title{
Current characteristics, challenges and coping strategies of young people with cystic fibrosis as they transition to adulthood
}

\author{
Authors: Kristina Askew, ${ }^{\mathrm{A}}$ Jade Bamford, ${ }^{\mathrm{B}}$ Nicholas Hudson, ${ }^{\mathrm{B}}$ Juliana Moratelli, ${ }^{\mathrm{B}}$ Rachel Miller, ${ }^{\mathrm{C}}$ Alan Anderson, ${ }^{\mathrm{D}}$ \\ Simon Doe ${ }^{E}$ and Stephen J Bourke ${ }^{E}$
}

This study provides detailed data on the current characteristics, perceptions and outcomes of 45 young people with cystic fibrosis (CF) as they transition into adulthood. Although many had severe disease, they generally coped well, found attendance at a transition clinic helpful and welcomed the increased independence of an adult healthcare environment. Levels of psychological distress were low with only $15.6 \%$ having anxiety and $6.7 \%$ depression. The main psychological coping strategy used was optimistic acceptance. Overall, most remained stable after transfer but $33 \%$ had some decline in lung function and $9 \%$ in nutritional status, requiring intensification of treatment. They had high levels of satisfaction with their relationships and life situations and $76 \%$ were in employment or education. These results are encouraging and as life expectancy improves, young adults with CF are coping well with transition into adulthood.

KEYWORDS: Coping strategies, cystic fibrosis, long-term conditions, transitional care, young adults

\section{Introduction}

Reports from the National Institute for Health and Care Excellence, the Royal College of Physicians and the Chief Medical Officer have focused on the needs of young people with long-term conditions, and have emphasised that young people should be involved in service design, delivery and evaluation. ${ }^{1-3}$ Young adults with cystic fibrosis (CF) face particular difficulties in coping with a life-limiting condition. Median life expectancy is about 40 years but is expected to improve beyond 50 years with developments in newborn screening, nutritional support, antibiotics, lung transplantation and new CF modulator

Authors: A principle clinical psychologist, Royal Victoria Infirmary, Newcastle upon Tyne, UK; ${ }^{B}$ assistant psychologist, Royal Victoria Infirmary, Newcastle upon Tyne, UK; C ${ }^{\text {specialist trainee, Royal }}$

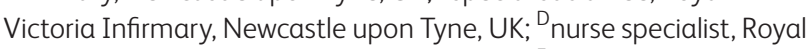
Victoria Infirmary, Newcastle upon Tyne, UK; ${ }^{E}$ consultant physician, Royal Victoria Infirmary, Newcastle upon Tyne, UK drugs. ${ }^{4-6}$ CF may affect key life situations, such as education, employment, independence and relationships. ${ }^{7}$ Men with CF are infertile and pregnancy poses challenges for women. ${ }^{8}$ Patients undertake a heavy treatment burden and normal teenage behaviours may reduce adherence with deleterious effects on their health. ${ }^{9}$

Transition care is a key focus for CF teams and is a process that addresses the medical, psychosocial, educational and vocational needs of these young adults as they enter adulthood. ${ }^{10,11}$ Transfer is the point at which responsibility for providing care moves from the paediatric team to the adult team. We undertook this study of young adults with CF to determine their current health and psychosocial status, to identify their perception of the challenges they face and to assess their needs and coping strategies.

\section{Methods}

Over a period of 2 years from the age of 15, patients and their parents attend the transition clinic at the adult CF centre at the Royal Victoria Infirmary for about $4-5$ visits. Consultations are still conducted by the paediatric multidisciplinary team (doctor, nurse, physiotherapist and dietician) with the corresponding adult clinician present. Patients are encouraged to speak to the clinicians independently and to learn to take responsibility for their treatments before transferring to the adult service, usually before the age of 18 years.

All patients who had transferred to the adult service in the previous 5 years were invited to participate in this study. They underwent a structured interview with a researcher using a standardised questionnaire that documented sociodemographic data, their experience of transition, the issues they identified in relation to their CF and its treatment, their knowledge and concerns about issues such as medications, prognosis, new treatments and reproductive health, the effect of CF on their lifestyle and relationships, and their access to information and support. They completed the hospital anxiety and depression scale (HADS). ${ }^{12}$ Coping strategies were assessed using the Ways of Coping scale, which is a validated CF-specific questionnaire in which the person evaluates 20 statements on methods of coping, indicating how much each statement applies to them on a 4 -point scale $(0=$ not at all; $1=$ a little, 
$2=$ a moderate amount, $3=$ a great deal). Of the statements, seven items link to 'optimistic acceptance', six to 'hopefulness', five to 'distraction' and two to 'avoidance'. Scores are adjusted to a scale of 0-100 for each of the four coping strategies. ${ }^{13}$ Higher scores indicate more frequent use of a coping style. Data on the complications of the patients' CF were obtained from their medical records. Lung function and weight were documented at transfer and 1 year later. ${ }^{14}$ The study was approved by the regional ethics committee and patients gave informed consent.

\section{Results}

Patients

Of 64 patients who transferred to the adult service over the previous 5 years, 45 patients ( $70 \%$ ) completed the study (Table 1); 27 were male. Some declined to participate or were away from home when the study was performed or 'too busy' for the interview. Their mean age at the time of interview was 20.7 (range 17-24) years; mean age at transfer to the adult service was 17 (range 15-21) years. Their mean forced expiratory volume in 1 second $\left(\mathrm{FEV}_{1}\right) \%$ predicted was $77 \%$ (range 26-120); mean body mass index (BMI) was $20.9 \mathrm{~kg} / \mathrm{m}^{2}$ (range 16.5-29.7); 53\% had chronic Pseudomonas aeruginosa, $6.6 \%$ had Burkholderia cepacia complex and $13 \%$ had nontuberculous mycobacterial lung infections; 25 (56\%) had an implanted central venous access device for administering antibiotics. Pancreatic insufficiency was present in 42 patients (93\%), seven (15.5\%) were receiving supplemental gastrostomy feeding and nine (23\%) had CF-related diabetes. One patient had undergone a liver transplant, one had suffered a pneumothorax, two had had colectomy for fibrosing colonopathy, and two had had episodes of distal intestinal obstruction. One had undergone termination of pregnancy.

\section{Experience of transition}

Most expressed satisfaction with the transition process: $87 \%$ felt that it had happened at the correct time and $80 \%$ found the

\section{Table 1. Patient characteristics}

$\begin{array}{ll}\text { Patient characteristics } & \mathbf{n}=45 \\ \text { Sex } & \begin{array}{l}\text { Male 27; } \\ \text { female 18 }\end{array} \\ \text { Mean age at transfer to adult service, years (range) } & 17(15-21) \\ \text { Mean age at interview, years (range) } & 20.7(17-24) \\ & \\ \text { Main complications } & \mathrm{n}(\%) \\ \text { Pancreatic insufficiency } & 42(93) \\ \text { CF-related diabetes } & 9(23) \\ \text { Gastrostomy feeding } & 7(16) \\ \text { Central venous access device } & 25(56) \\ \text { Pseudomonas aeruginosa } & 24(53) \\ \text { Non-tuberculous mycobacteria } & 6(13) \\ \text { Burkholderia cepacia complex } & 3(7) \\ \text { Allergic aspergillosis } & 12(27)\end{array}$

transition clinic helpful. Positive themes relating to transition were

> it was useful to meet the adult team with the paediatric team still present

$>$ the increased independence in their own care

$>$ receiving clinic letters addressed to them rather than to their parents

$>$ having involvement in decision making

$>$ the adult CF team speaking directly to them rather than via their parents

$>$ a more mature environment.

Negative themes relating to transition included

$>$ regret at leaving the paediatric team

$>$ concerns about the risk of infection in a new environment

$>$ concern that there might be differences in care

$>$ for some, concerns about having to travel to the regional centre.

In the paediatric clinic, $94 \%$ attended the clinic with a parent but after transfer only $49 \%$ attended with a parent, $33 \%$ usually attended alone and $18 \%$ with a partner. $91 \%$ reported a preference to advocate for themselves but some commented that they would like the support of a parent if there was 'something major happening', and 93\% reported that they found their relationship with their family 'very or extremely' supportive.

Although 69\% indicated that they had sufficient information about their CF and the adult services, $31 \%$ wanted more information about reproductive health, exercise and CF, future developments in treatments and undertaking travel abroad. Sources of information included their medical team, websites, social media, online forums, leaflets and a CF Trust magazine; 97\% accessed social media and 50\% accessed the CF Trust website. For support, $84 \%$ reported that they found talking to their doctor 'very or extremely' helpful and $80 \%$ found talking to a nurse 'very or extremely' helpful.

\section{Treatment adherence}

Most patients felt that they were knowledgeable about their medications, nutrition and physiotherapy, and 66\% felt that they were 'very or extremely independent' in taking treatments. Self-reported adherence was reasonably high: $82 \%$ 'never or rarely' missed pancreatic enzyme supplements, $63 \%$ 'never or rarely' missed nebulised treatments (antibiotics, mucolytic medications) and 51\% 'never or rarely' missed physiotherapy. Reasons for missing treatments included time pressures, breaks in routine (eg holidays, being away from home), getting up late or discomfort in taking medications in front of others; $18 \%$ reported that their adherence had deteriorated after transfer to the adult service, $58 \%$ had remained the same and $24 \%$ had improved.

\section{Psychological wellbeing and coping strategies}

The HADS consists of seven questions for anxiety and seven questions for depression. Each item is scored on a scale from $0-3$, giving total scores between $0-21$ for anxiety and depression. Higher scores indicate greater severity; $8 / 21$ is the cut-off score for clinical significance. ${ }^{12}$ The overall mean score for anxiety was low at 4.02 (range $0-18$, SD 4.2) but seven patients $(15.6 \%)$ demonstrated significant anxiety. The overall 


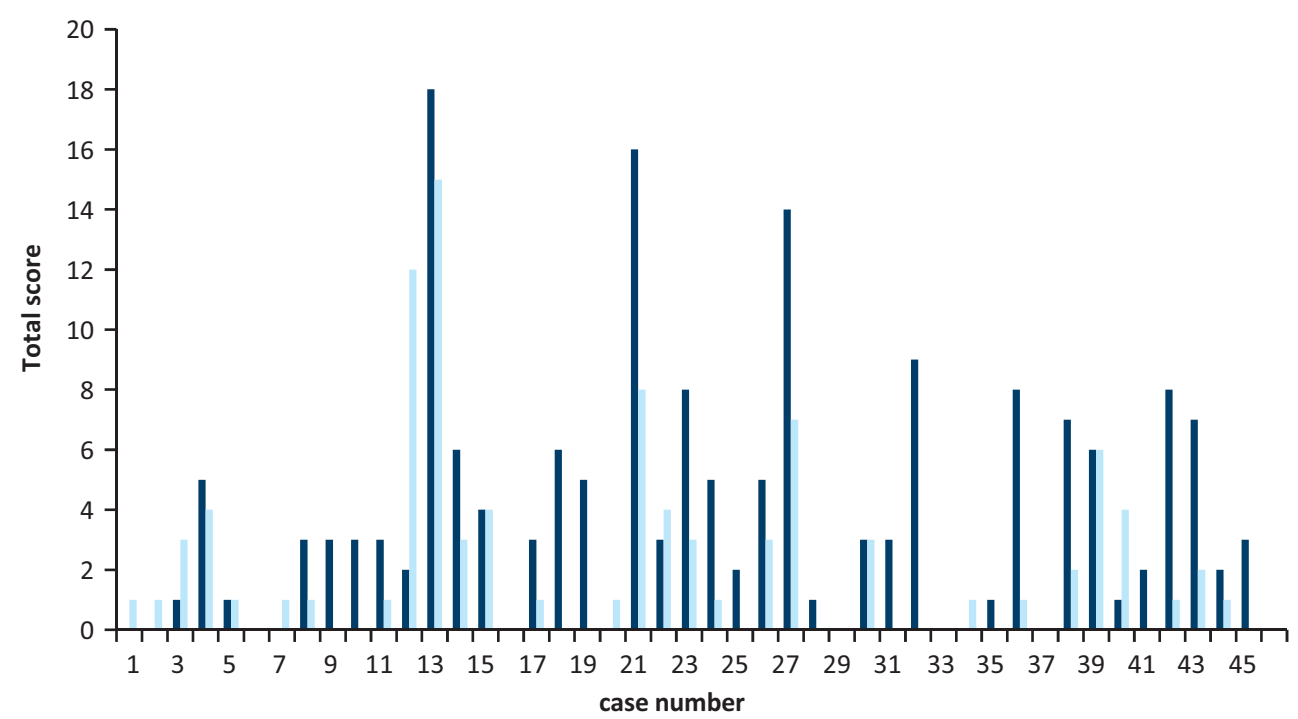

Fig 1. Individual hospital anxiety and depression scale (HADS) scores. ${ }^{12}$

mean score for depression was also low at 2.18 (range 0-15, SD 0.48 ) but three patients $(6.7 \%)$ had significant depression (Fig 1).

The most common coping style reported was optimistic acceptance, with $84.4 \%$ of patients using this as their main way of coping. Avoidance was used as the main strategy by $8.8 \%$, distraction by $2.2 \%$ and hopefulness by $2.2 \%$. Patients generally employed more than one strategy. Mean scores were 77.9 for optimistic acceptance, 38.2 for hopefulness, 38.8 for distraction and 33.3 for avoidance (Table 2). Fig 2 shows the individual coping strategies, listed in ascending order of the mean scores.

\section{Clinical, vocational and life satisfaction outcomes}

After transfer, overall mean $\mathrm{FEV}_{1} \%$ predicted remained stable, changing from $76.6 \%$ (range 26.4-119.6) at transfer to $75.4 \%$ (range 19-111) 1 year later (Table 3 ). However, there was individual variability with 15 patients (33\%) having a deterioration in $\mathrm{FEV}_{1}$ of more than $5 \%$ at 1 year, eight patients (18\%) showing an improvement of more than 5\%, and $22(49 \%)$ remaining stable. Mean BMI changed from $20.8 \mathrm{~kg} / \mathrm{m}^{2}$ (range 16.5-29.7) at transfer to $21.2 \mathrm{~kg} / \mathrm{m}^{2}$ (range $17.3-29.2)$ at 1 year; 11 patients (24\%) showed an improvement in BMI of more than $1 \mathrm{~kg} / \mathrm{m}^{2}$ at 1 year, four (9\%) showed a

Table 2. Mean scores for coping strategies ${ }^{13}$

$\begin{array}{lll} & \begin{array}{l}\text { Proportion of patients } \\ \text { using as main coping } \\ \text { style }\end{array} & \begin{array}{l}\text { Mean scores } \\ (\mathbf{0}-100 \text { scale) }\end{array} \\ \text { Optimistic acceptance } & 84 \% & 77.9 \\ \text { Avoidance } & 8.8 \% & 33.3 \\ \text { Distraction } & 2.2 \% & 38.8 \\ \text { Hopefulness } & 2.2 \% & 38.2\end{array}$

deterioration in BMI of more than $1 \mathrm{~kg} / \mathrm{m}^{2}$, and $30(67 \%)$ remained stable. Thirty four patients $(76 \%)$ were either in employment or education, $11 \%$ were unemployed and $9 \%$ were looking for work. Overall, $74 \%$ felt that CF had no effect on their social or family lives and $77 \%$ felt that it had no effect on their friendships. However, $52 \%$ felt that admission to hospital, treatments and symptoms had a negative impact on work or studies. Many commented on the negative impact CF had on travelling abroad, particularly because of the cost of health insurance and problems with excess luggage to carry medications. Most were considering the effect of CF on having children and some were ready to seek information about this. One woman had a child of her own and $54 \%$ of patients intended to have children. Some were unsure or thought that they were too young to consider parenthood. Overall, 79\% of patients indicated an awareness of the importance of genetic testing of a partner, $83 \%$ were aware of the importance of contraception and $61 \%$ of the benefits of planning a pregnancy.

\section{Discussion}

This study provides detailed data on the current characteristics, perceptions and outcomes of young people with CF as they enter adulthood. They have a range of disease severity but many have impaired lung function and nutrition with significant CF complications and daunting medical problems. Despite having a life-limiting disease, they are functioning well in their lives, gaining independence, undertaking further education and employment, forming relationships and planning to undertake parenthood. ${ }^{15,16}$ They are ready to discuss issues such as pregnancy, fertility and sexual health, and they want more information about new treatments for CF, risks of crossinfection and undertaking travel with CF. They are generally satisfied with the transition process although they regret leaving the paediatric team. They have a positive attitude to increased independence, an adult environment for healthcare and participation in decision making. They are entering the adult 




Fig 2. Coping strategies employed by patients with cystic fibrosis (CF). Listed in ascending order of the mean scores reported for each strategy. ${ }^{13}$ international epidemiological study in patients with CF showed that depression and anxiety were 2-3 times higher than reported in community samples, with elevated levels of anxiety in $32 \%$ of adults and $22 \%$ of adolescents, and elevated levels of depression in $19 \%$ of adults and $10 \%$ of adolescents. ${ }^{21}$ In our study, levels of psychological distress were lower and this may indicate good preparation for transition by the paediatric services and improved optimism as new treatments for CF are developed. Other studies confirm the complex interactions between psychological distress, coping strategies, quality of life and the person's perceptions and beliefs. ${ }^{22,23}$

In our study, self-reported adherence to treatments was reasonably good with patients reporting a higher level of adherence to tablet medications than to inhaled therapies and physiotherapy. They reported a good level of knowledge about treatments, but had to fit these treatments into a busy lifestyle. As they undertake responsibility for their own treatments there is a risk that adherence may deteriorate. Most reported that adherence remained the same or improved, but $18 \%$ reported deterioration. Similarly, key clinical parameters of $\mathrm{FEV}_{1}$ and BMI largely remained stable or improved during this crucial phase; however, $33 \%$ showed some deterioration in lung function and $9 \%$ showed deterioration in BMI. CF is a progressive disease such that some deterioration may occur even with optimal adherence, but there is a need to focus on those showing a decline so that treatment and support can be intensified.

Having a severe progressive disease can also have an adverse effect on employment, social relationships, self-esteem and ambition. ${ }^{7,24}$ In this study, however, young adults were functioning well, with $76 \%$ in employment or education and high levels of life satisfaction. Despite this, $52 \%$ felt that CF had a negative impact on education, employment and certain life situations. They require additional support in dealing with issues such as careers advice, employment rights, financial planning and travel insurance.

\section{Conclusions}

Transition services for young adults with CF are now well developed. Our study is encouraging and suggests that they are 
managing well in the transition to adulthood. Their clinical and life satisfaction outcomes are influenced by a complex interplay of many variables including psychosocial status, coping strategies, support structures and adherence to treatments, and this requires further evaluation. However, clinical teams need to be aware of these issues and advice and care must be specific to each patient. Many of these issues may be equally applicable to other young adults with long-term medical conditions.

\section{Author contributions}

$\mathrm{KA}, \mathrm{SD}, \mathrm{AA}$ and SJB designed the study. KA, JB, NH, JM and RM undertook the interviews. KA, NH, RM and SJB analysed the data and wrote the manuscript, which was approved by all authors.

\section{Conflicts of interest}

The authors have no conflicts of interest to declare.

\section{References}

1 National Institute for Health and Care Excellence. Transition from children's to adults' services for young people using health or social care services. NICE guideline No 43. London: NICE, 2016.

2 Royal College of Physicians. Position statement: Young adult and adolescent patient care. London: RCP, 2014.

3 Department of Health. Chief Medical Officer's annual report 2012: Our children deserve better: prevention pays. London: $\mathrm{DoH}$, 2013.

4 Carr S, Cosgriff R, Rajabzadeh-Heshejin. UK Cystic Fibrosis Registry 2015 annual data report. London: Cystic Fibrosis Trust, 2016.

5 Dodge JA, Lewis PA, Stanton M, Wilsher J. Cystic fibrosis mortality and survival in the UK:1947-2003. Eur Respir J 2007;29:522-6.

6 Lane M, Doe S. A new era in the treatment of cystic fibrosis. Clin Med 2014;14:76-8.

7 Targett K, Bourke S, Nash E et al. Employment in adults with cystic fibrosis. Occup Med 2014;64:87-94.

8 Staub MO, Leon K, Robin NH. Educating the adolescent and young adult with cystic fibrosis about their reproductive risks and options. Chest 2013;143:580-1.

9 Kazmerski TM, Miller E, Abebe KZ et al. Patient knowledge and clinic attendance in adolescent patients with cystic fibrosis. Pediatr Allergy Immunol Pulmonol 2015;28:107-11.

10 Blum RW, Garell D, Hodgman CH et al. Transition from childcentred to adult health-care systems for adolescents with chronic conditions. A position paper of the Society for Adolescent Medicine. J Adolesc Health 1993;14:570-6.

11 Merrick H, McConachie H, Le Couteur A et al. Characteristics of young people with long term conditions close to transfer to adult health services. BMC Health Serv Res 2015;15:435.

12 Zigmond AS, Snaith RP. The hospital anxiety and depression scale. Acta Psychiatr Scand 1983;67:361-70.

13 Abbott J, Dodd M, Gee L, Webb K. Ways of coping with cystic fibrosis: implications for treatment adherence. Disabil Rehabil 2001;23:315-24.

14 Quanjer PH, Stanojevic S, Cole TJ et al. Multi-ethnic reference values for spirometry for the 3-95 year age range: the global lung function 2012 equations. Eur Respir J 2012;40:1324-43.

15 Wicks E. A patient's journey: cystic fibrosis. BMJ 2007;334:1270-1.

16 Besier T, Schmitz TG, Goldbeck L. Life satisfaction of adolescents and adults with cystic fibrosis: impact of partnership and gender. J Cyst Fibros 2009;8:104-9.

17 Bryon M, Madge S. Transition from paediatric to adult care: psychological principles. J Royal Soc Med 2001;40:5-7.

18 Kreindler JL, Miller VA. Cystic fibrosis: addressing the transition from pediatric to adult-oriented health care. Patient Prefer Adherence 2013;7:1221-6.

19 Nazareth D, Walshaw M. Coming of age in cystic fibrosis - transition from paediatric to adult care. Clin Med 2013;13:482-6.

20 Boyle MP, Farukhi Z, Nosky ML. Strategies for improving transition to adult cystic fibrosis care, based on patient and parent views. Pediat Pulmonol 2001;32:428-36.

21 Quittner AL, Goldbeck L, Abbott J et al. Prevalence of depression and anxiety in patients with cystic fibrosis and parent givers: results of the international depression epidemiological study across nine countries. Thorax 2014;69:1090-7.

22 Bucks RS, Hawkins K, Skinner TC et al. Adherence to treatment in adolescents with cystic fibrosis: the role of illness perceptions and treatment beliefs. J Pediatric Psychology 2009;34:893-902.

23 Gee L, Abbott J, Conway S, Etherington C, Webb A. Quality of life in cystic fibrosis: the impact of gender, general health perceptions and disease severity. J Cyst Fibros 2003;2:206-13.

24 Higham L, Ahmed S, Ahmed M. Hoping to live a 'normal' life whilst living with unpredictable health and fear of death: impact of cystic fibrosis on young adults. J Genet Counsel 2013;22:374-83.

Address for correspondence: Dr S J Bourke, Royal Victoria Infirmary, Queen Victoria Road, Newcastle upon Tyne NE1 4LP, UK.

Email: Stephen.Bourke@nuth.nhs.uk 